\title{
Study on Coastline Changes of Xiamen City Based on Remote Sensing Images
}

\author{
Yanfang Qin*, Lin Ye and Siming Chen \\ College of Ocean Science, Minjiang University, Fuzhou, Fujian, 350108, China
}

\begin{abstract}
Based on the Landsat remote sensing data, this paper had monitored the coastline changes of Xiamen city in recent 20 years. By extracting the coastline vector data of 1999, 2005, 2011 and 2017 respectively, the spatio-temporal characteristics of coastline changes on coastline length, change rate and land change area were analyzed, and the main driving factors were analyzed combined with the land use changes in the coastal swing area. The results show that: the total length of Xiamen's coastline increased from $235.16 \mathrm{~km}$ to $264.98 \mathrm{~km}$ during $1999-2017$, and the land area increased from $1558.84 \mathrm{~km}^{2}$ to 1594.29 $\mathrm{km}^{2}$. The most significant changes occurred in Xiang'an district and Huli district with the coastline length increased by $16.38 \%$ during $2011-2017$ and $22.14 \%$ during $1999-2005$ respectively, while the changes were not very conspicuous in other areas. According to the land use changes in the coastal areas, the coastline changes in Xiamen City were mainly related to the expansion of construction land and port constructions in Haicang district, Xiang'an district and Huli district, as well as the expansion of aquaculture in the Xiang'an district.
\end{abstract}

\section{Introduction}

Coastline, the boundary of land and sea, is vulnerable to the natural processes, such as coastal erosion-accretion and sea level changes, and human activities[1-3].The coastline changes will directly affect the intertidal zones and wetland ecosystems, resulting in the environment evolution in coastal zone. It will also lead to changes in the nature of river channels and navigation conditions, resulting in changes in passenger and cargo volumes in some regions, which will have a certain impact on the macro-economy of the region. Coastline mapping and change detection are, therefore, becoming a fundamental work for coastal resource management, environmental protection of coastal zone and coastal sustainable development[4].

Since the establishment of the special economic zone in 1980, Xiamen's economy continues to develop at a high speed, which has led to extensive land reclamation and caused significant changes of coastline[5-6]. In 2015, the government put forward an initiative to jointly build the 21 st century maritime silk road and the silk road economic belt. As a major hub city connecting the One Belt and One Road, Xiamen City has actively built the key areas for connectivity, trade and cultural exchanges with other countries and regions[7]. The major ongoing construction projects include: construction of Xiang 'an international airport with a planning land use of $46 \mathrm{~km}^{2}$ and a reclamation area of $17 \mathrm{~km}^{2}$; port infrastructure constructions, such as the third stage of Wutong Ferry Terminal and the port facilities improvement of Wuyuan Bay Yacht Marina; comprehensive construction of exchange hubs for connectivity, economic-trade cooperation and cultural exchange with regions and countries along the One Belt and One Road, such as "China-Asean Maritime Cooperation Center". All of these will have a profound impact on the change of Xiamen coastline and coastal ecological environment[89].

Remote sensing, which has the advantage of real-time synchronously obtaining spatio-temporal information of different scales, has played an important role in coastline survey and dynamic monitoring. In recent years, many scholars have done a lot of research on coastline extraction by using remote sensing methods and proposed a variety of extraction algorithms[10-12]. In general, the coastline extracted from remote sensing imagery with finer spatial resolution is more likely to achieve higher accuracy [10], and an increasing number of high spatial resolution remote sensing images were used for effective coastline extraction[13-15]. However, there were still a large number of scholars choose the Landsat series imagery, because of its free access, large revisit coverage and long-term data record. In real applications, Landsat series images acquired from sensors of Landsat 1-3 Multi-spectral Scanner (MSS), Landsat 4-5 Thematic Mapper (TM), Landsat-7 Enhanced Thematic Mapper Plus (ETM+) and Landsat-8 Operational Land Imager (OLI) are useful data for extracting coastline, which can provide a time series of more than 40 years and be very helpful for studying the coastline changes. Lira and Taborda [16] summarized the advances of coastline extraction from available freeaccess satellite imagery, and showed that the Landsat

$\overline{{ }^{*} \text { Corresponding author's e-mail: yanfqin@qq.com }}$ 
imagery offers the best compromise between potential and availability to understand coastal dynamic features. Pardo-Pascual et al. [17] evaluated how the storms impact the sandy beaches and the beach recovery process by describing the coastline positions obtained from Landsat TM and ETM+. Guo et al. [18] used the Landsat Thematic Mapper (TM) images and Landsat 8 OLI acquired from 1985 to 2015 to presents a track of coastline changes at Tampa Bay and Xiangshan Harbor during the last 30 years and analyzed the probable causes. Wang et al. [19] used Landsat MSS, TM, ETM+ and OLI images for coastline detection along Ningbo City from 1976 to 2015. Wang et al. [20] applied a pansharpening algorithm to generate a fused fine spatial resolution MS image, which is used finally to extract coastline with automatic water index method.

Overall, current coastline extraction methods using Landsat imagery are focusing on automatic extraction, and a number of new algorithms are introduced to improve the accuracy, but the results still need to be revised by manual interaction methods. In this paper, 4 phases of coastline vector data were obtained through the multi-band spectral relationship method based on Landsat images, combined with manual revision based on high-resolution Google Earth images to improve the accuracy. On this basis, spatial analysis was conducted to study the changes in length, tortuousness and land area, as well as the main driving factors of Xiamen's coastline change in the past 20 years from the perspective of land use type change in coastal areas.

\section{Methods}

\subsection{Study area}

Xiamen, subordinate to Fujian province, is located in the west coast of the Taiwan Strait, composed of the mainland area along Xiamen Bay, Xiamen Island, Gulangyu and other islands, including 6 administrative districts of Huli, Siming, Haicang, Jimei, Tong'an and Xiang'an, with a resident population of 3.92 million. The city's climate belongs to the subtropical monsoon climate, pleasantly moist and mild throughout the year, with an annual average temperature $21^{\circ} \mathrm{C}$ and an annual average precipitation 1,200 $\mathrm{mm}$.

The coastlines studied in this paper include the coastline of mainland and all islands. The coastline changes due to natural factors are very slow. However, with the continuous development of economy, the reclamation areas in Xiamen coastal zone keep expanding, such as reclamation of aquaculture ponds, construction of coastal ports, etc. Under the influence of human activities, the change rate of coastline is getting faster and faster [6].

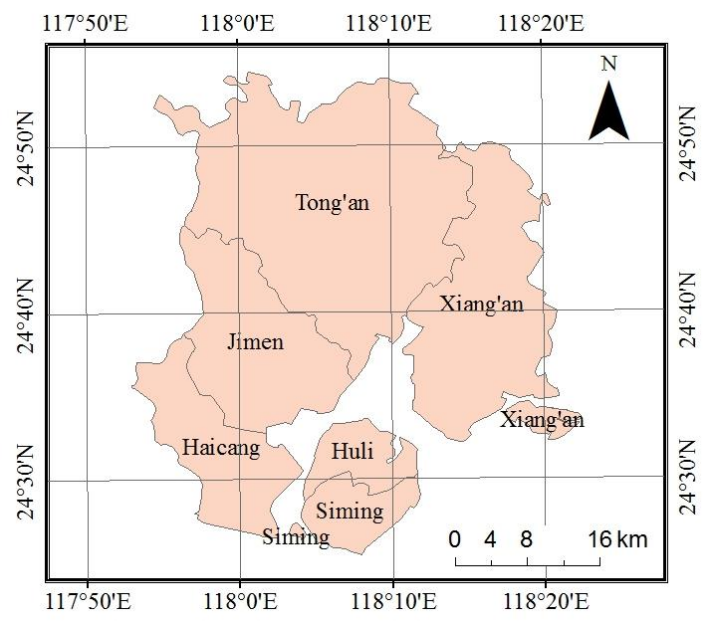

Figure 1. Overview of the Xiamen City.

\subsection{Data collection and pre-processing}

and processed to extract multi-year coastline information. The information of images was listed in Table 1.

Landsat TM, ETM+ and Landsat8 OLI/TIRS images acquired in 1999, 2005, 2011 and 2017 were collected

Table 1. List of remote sensing image data.

\begin{tabular}{ccccc}
\hline Acquisition Date & Satellite & Sensor & Spatial Resolution $(\mathrm{m})$ & Cloud Cover (\%) \\
\hline $1999-09-07$ & Landsat7 & ETM+ & 30 & 5.35 \\
$2005-07-13$ & Landsat5 & TM & 30 & 2.5 \\
$2011-09-16$ & Landsat5 & TM & 30 & 1.67 \\
$2017-10-02$ & Landsat8 & OLI & 30 & 1.52 \\
\hline
\end{tabular}


In order to further improve the accuracy of coastline extraction and classification, atmospheric correction and enhancement processing were carried out on the remote sensing images. Besides, due to the absence of other geographic reference data, fine geometric corrections on the remote sensing images of 1999, 2005 and 2011 were carried out by taking the OLI image in 2017 as standard to ensure the comparability of each phase.

In addition, 1:100,000 standard vector map of Chinese county boundary (2015) was used to extract the inland boundary vector data to form the full Xiamen administrative boundaries combined the RS derived coastlines.

\subsection{Coastline extraction}

The multi-band spectral relationship method, put forward by Zhou et al. [21], was used to extract coastlines in this paper. Through the analysis of spectral reflectance curves of water and other surface types in TM image, it was found that the water bodies had a typical feature: the sum of reflectance values of green band plus red band was larger than those of near-infrared band plus middleinfrared band, which was completely different from other surface types. Therefore, the multi-band spectral relationship method of water body extraction was proposed as follows:

$$
(G R E E N+R E D)-(N I R+M I R)>X
$$

Where, GREEN, RED, NIR and MIR were respectively the reflectance values of green band, red band, near-infrared band and middle-infrared band. $X$ was the threshold that can distinguish water bodies from other ground objects (it could be 0 in general).

Based on the threshold $X$, water-land binary images could be produced, and the sea-land demarcation lines could be obtained through transformation algorithms of raster-to-vector and polygon-to-line, supplemented with smoothing processing to eliminate the sawtooth error of raster-to-vector transformation. In addition, the vector data was also needed to be revised by human interaction to produce more accurate results, which eventually become the coastlines of Xiamen.

\subsection{Coastline change characteristics}

According to the administrative divisions of Xiamen, the coastline was divided into 6 sections: Huli, Siming, Haicang, Jimei, Tong'an and Xiang'an. The changes of each section in different period can be used to analyze the variation in different administrative districts.

2.4.1 Length. In order to objectively and accurately compare the temporal and spatial coastline changes, the annual average change of coastline length in a certain period was adopted:

$$
V=\frac{L_{j}-L_{i}}{j-i}
$$

Where, $V$ was the average change rate of coastline length between year $i$ and year $j ; L_{i}$ was the length of the coastline in year $i ; L_{j}$ was the length of coastline in year $j$.

2.4.2 Land area. The coastlines derived from remote sensing images were merged with the inland boundary of Xiamen administrative divisions to form the whole area, so as to obtain the total land area in 4 phases. The changes of the land area in different periods were obtained through overlay analysis.

\subsubsection{Land cover/land use change in coastal swing} area. For studying the development and utilization in coastal area, or other human activities related to coastline change, the land cover and land use information in coastal swing area was obtained. Land use types in Xiamen can be divided into 5 classes: forest, cultivated land, construction land, aquaculture and water bodies. However, not all the 5 types were available in the coastal swing zone. Therefore, visual interpretation was carried out for each patch in the coastal swing zone, and the type information of corresponding increase or decrease was obtained combined with the coastline changes in two adjacent periods. Furthermore, for the extracted individual types which were not very clear in Landsat images, the photos and high-resolution remote sensing images shared in Google maps were used for auxiliary judgment.

\section{Results}

\subsection{Coastline change characteristics}

The coastlines of Xiamen in 4 phases during 1999-2017 were shown in figure 2 . The significant change of coastline was mainly concentrated in Haicang, Huli and Xiang'an district. Particularly, the outward expansion in Dadeng Island was very obvious during 2011-2017.

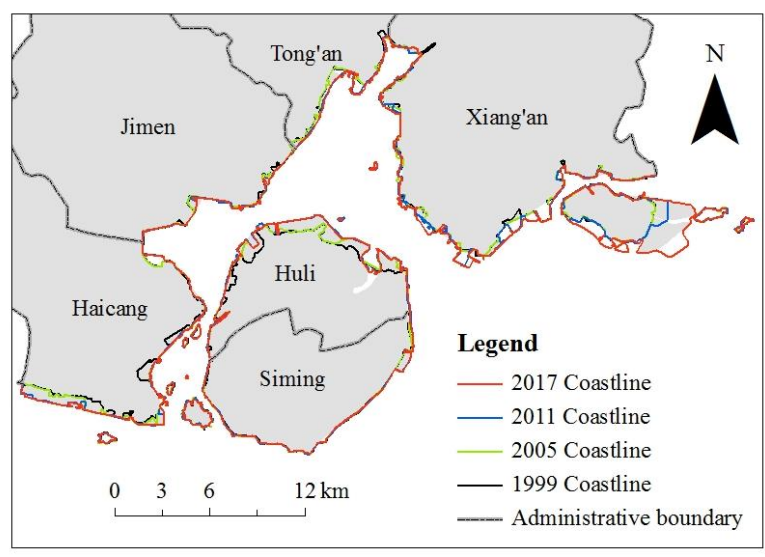

Figure 2. Coastline changes in Xiamen from 1999 to 2017.

3.1.1 Length. From 1999 to 2017, the total length of coastline in Xiamen increased from $235.16 \mathrm{~km}$ to 264.98 $\mathrm{km}$, with a growth rate of $12.68 \%$, and the significant changes were mainly during 2005-2017 (as shown in 
table 2). Generally speaking, the increase of coastline was mainly related to large-scale reclamation projects, while the decrease was mainly due to the transformation of natural tortuous coastline into relatively neat artificial coastline.

According to table 2, the main changes from 1999 to 2005 were that the shoreline of Haicang, Huli and Xiang'an moved towards the sea. Furthermore, the coastlines in Haicang and Xiang'an became more straight with a decrease in length, while it in Huli had increased in the sinuosity and the length increased from $31.8 \mathrm{~km}$ to $38.84 \mathrm{~km}$, with a growth rate of $22.14 \%$.

During 2005-2011, the most significant change occurred in Xiang'an district, especially in Dadeng Island located in the southeast of Xiang'an district. Due to large-scale reclamation projects, the coastline length increased from $80.14 \mathrm{~km}$ to $89.14 \mathrm{~km}$.

From 2011 to 2017, Tong'an and Xiang'an showed the most significant changes. In Xiang'an district, the coastline length increased from $89.14 \mathrm{~km}$ to $103.74 \mathrm{~km}$, with a growth rate of $16.38 \%$.

Table 2. The change of coastline length(unit: $\mathrm{km}$ ) and average annual change rate (unit: $\mathrm{km} / \mathrm{a}$ ).

\begin{tabular}{cccccccc}
\hline & Haicang & Huli & Jimei & Siming & Tong'an & Xiang'an & Whole Xiamen \\
\hline \multirow{2}{*}{$1999-2005$} & -3.46 & 7.04 & -1.75 & -0.29 & -1.03 & -3.54 & $\mathbf{- 3 . 0 3}$ \\
& -0.58 & 1.17 & -0.29 & -0.05 & -0.17 & -0.59 & $\mathbf{- 0 . 5 1}$ \\
\hline \multirow{2}{*}{$2005-2011$} & -0.09 & 2.42 & -0.17 & 1.54 & -1.65 & 9 & $\mathbf{1 1 . 0 5}$ \\
& -0.02 & 0.40 & -0.03 & 0.26 & -0.28 & 1.50 & $\mathbf{1 . 8 4}$ \\
\hline \multirow{2}{*}{$2011-2017$} & 2.64 & -1.35 & 0.26 & -0.07 & 5.72 & 14.6 & $\mathbf{2 1 . 8}$ \\
& 0.44 & -0.23 & 0.04 & -0.01 & 0.95 & 2.43 & $\mathbf{3 . 6 3}$ \\
\hline \multirow{2}{*}{ Total } & $\mathbf{- 0 . 9 1}$ & $\mathbf{8 . 1 1}$ & $\mathbf{- 1 . 6 6}$ & $\mathbf{1 . 1 8}$ & $\mathbf{3 . 0 4}$ & $\mathbf{2 0 . 0 6}$ & $\mathbf{2 9 . 8 2}$ \\
& $\mathbf{- 0 . 0 5}$ & $\mathbf{0 . 4 5}$ & $\mathbf{- 0 . 0 9}$ & $\mathbf{0 . 0 7}$ & $\mathbf{0 . 1 7}$ & $\mathbf{1 . 1 1}$ & $\mathbf{1 . 6 6}$ \\
\hline
\end{tabular}

3.1.2 Land area. From 1999 to 2017, the land area of Xiamen increased from $1558.84 \mathrm{~km}^{2}$ to $1594.29 \mathrm{~km}^{2}$, with a total land area added up to $35.45 \mathrm{~km}^{2}$. As shown in table 3 and figure 3 , it increased by $8.46 \mathrm{~km}^{2}$ during
1999-2005, mainly distributed in Haicang and Huli district; during 2005-2011, it increased by $15.62 \mathrm{~km}^{2}$, with a relatively evenly distribution in the whole region; during 2011-2017, it increased by $11.37 \mathrm{~km}^{2}$, which mainly occurred in Xiang'an district.

Table 3. Statistics of land area change from 1999 to 2017 (unit: $\mathrm{km}^{2}$ ).

\begin{tabular}{cccccccc}
\hline & Haicang & Huli & Jimei & Siming & Tong'an & Xiang'an & Whole Xiamen \\
\hline $1999-2005$ & 3.06 & 4.44 & 0.24 & 0.37 & 0.25 & 0.1 & $\mathbf{8 . 4 6}$ \\
$2005-2011$ & 3.59 & 3.65 & 0.77 & 0.94 & 2.16 & 4.5 & $\mathbf{1 5 . 6 2}$ \\
$2011-2017$ & 0.32 & -0.39 & 0 & -0.14 & 0.36 & 11.22 & $\mathbf{1 1 . 3 7}$ \\
Total & $\mathbf{6 . 9 7}$ & $\mathbf{7 . 7}$ & $\mathbf{1 . 0 1}$ & $\mathbf{1 . 1 7}$ & $\mathbf{2 . 7 7}$ & $\mathbf{1 5 . 8 2}$ & $\mathbf{3 5 . 4 5}$ \\
\hline
\end{tabular}

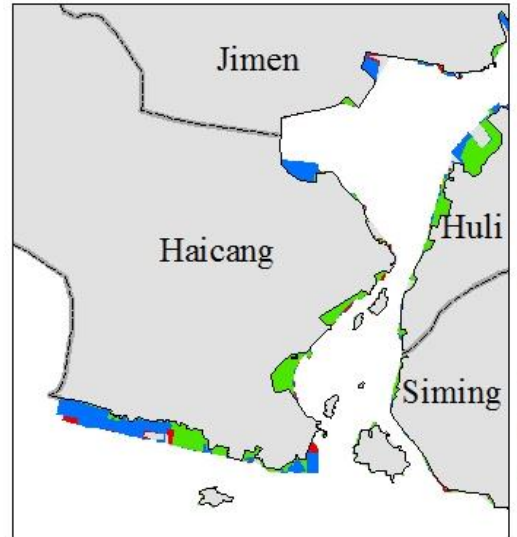

$\begin{array}{llll}0 & 2 & 4 & 8 \mathrm{~km}\end{array}$

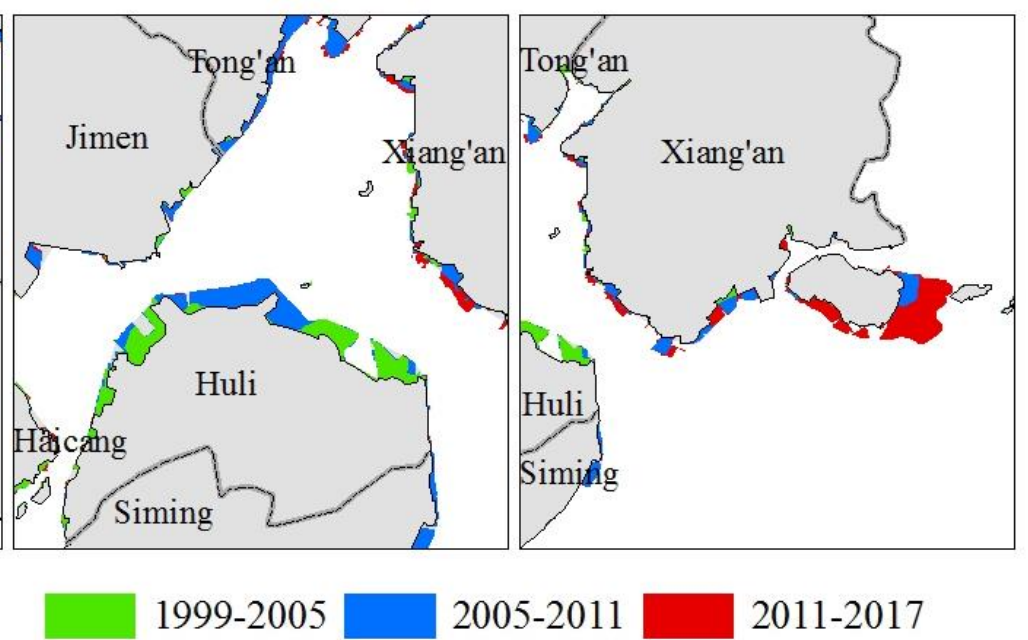

Figure 3. Partial land changes. 
Overall, the most obvious expansion areas were mainly distributed in Haicang district and Xiang'an district. Especially in eastern and southern Dadeng island, extensive reclamation projects such as Xiang'an international airport construction made the island land area increase by almost double. In Haicang district, the significant increase in land area from 2005 to 2011 was mainly due to the construction of bonded port area in the south coast.

\subsection{Land use and land cover change in the coastal swing area}

To further analyze the reasons for coastline change, the land cover types of the coastline swing area were acquired by means of visual interpretation, assisted with high-resolution images and shared photos from Google Earth. The main changes were: (1) the original sea areas were turned into construction lands by reclamation, which occupied the largest area, or became new aquaculture areas; (2) the original aquaculture areas were abandoned and turned into construction lands or sea areas; and (3) small areas of construction land that had been rezoned and flooded by seawater.

During 1999-2005, the new construction land area reached $6.75 \mathrm{~km}^{2}$, accounting for $79.8 \%$ of the total new land area. Among the new construction land, 34.2\% was distributed in Haicang and $61.6 \%$ in Huli (see figure 4).

During 2005-2011, the new construction land area reached $12.74 \mathrm{~km}^{2}$, accounting for $81.6 \%$ of the total new land area. Among the new construction land, 23.3\% was distributed in Haicang, 27.1\% in Huli, $15.2 \%$ in Tong'an and $23.1 \%$ in Xiang'an (see figure 5). In addition, $2.86 \mathrm{~km}^{2}$ aquaculture areas were added in Xiang'an district.

During 2011-2017, only in Xiang'an district, the construction land was increased by $10.82 \mathrm{~km}^{2}$, accounting for $95.3 \%$ of the total added value of construction land. Besides, a small amount of construction land had been submerged by the sea (see figure 6).

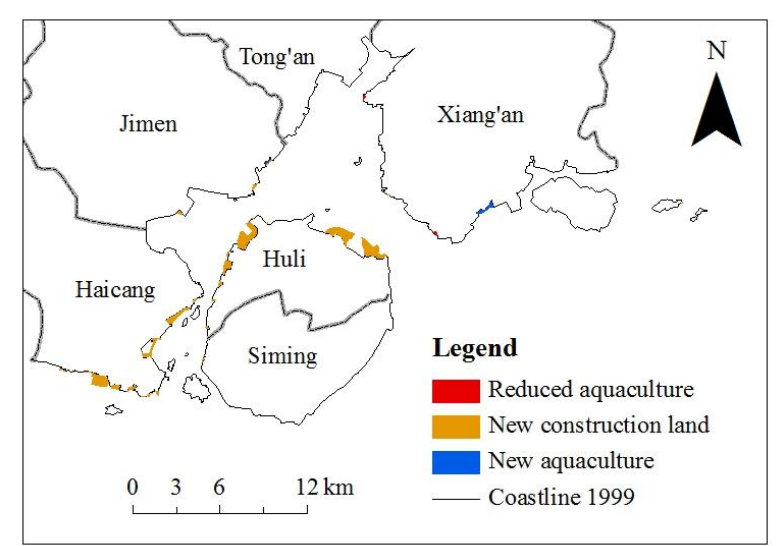

Figure 4. Land use and land cover change in the coastal swing area of 1999-2005.

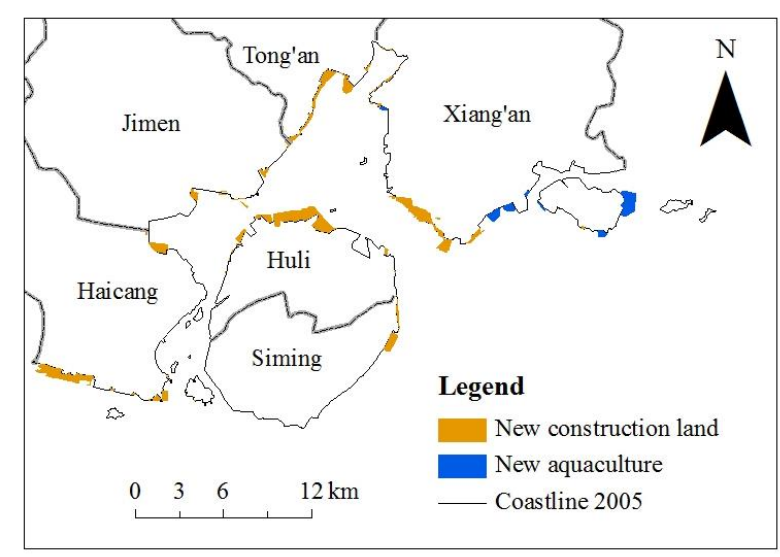

Figure 5. Land use and land cover change in the coastal swing area of 2005-2011.

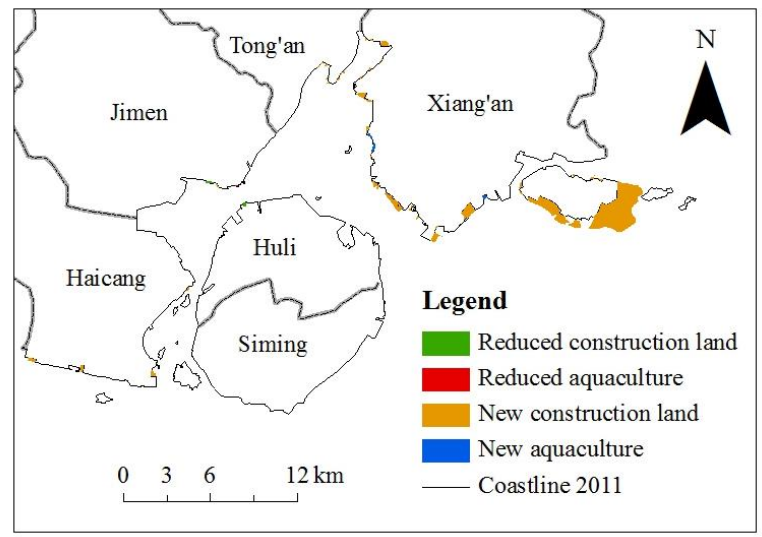

Figure 6. Land use and land cover change in the coastal swing area of 2011-2017.

\section{Conclusions}

In this paper, 4 phases of Landsat images were selected to analyze the coastline change characteristics of Xiamen in the past 20 years, and the following main conclusions were:

(1) During 1999-2017, the coastline of Xiamen increased significantly, with growth $11.05 \mathrm{~km}$ and 21.8 $\mathrm{km}$ during 2005-2011 and 2011-2017, and the average annual change rate was $1.84 \mathrm{~km} / \mathrm{a}$ and $3.63 \mathrm{~km} / \mathrm{a}$, respectively. The most obvious growth occurred in Xiang'an district from 2005 to 2017 and Huli district from 1999 to 2005. The remarkable changes in Xiang'an district was mainly due to the large scale of reclamation for the new airport and airbase city construction in Dadeng island. The changes in Huli district were also owing to large-scale reclamation, such as the Xiangyu port and Xiangyu free trade zone in the west, Gaoqi international airport in the north, and Wuyuanwan new business centers and residential areas in the northeast.

(2) The land area increased from $1558.84 \mathrm{~km}^{2}$ to $1594.29 \mathrm{~km}^{2}$ during 1999-2017, with an overall increase of $35.45 \mathrm{~km}^{2}$. The newly added land area was mainly distributed in Xiang'an, Haicang and Huli district. Since 1999, the construction land in coastal areas had been continuously expanded, the ports had been further built, 
and the aquaculture area in Xiang'an district had also increased significantly.

(3) With the economic development of Xiamen city, the continuous expansion of urban land, had sharply reduced the land area suitable for development, and the construction began to expand to the sea, causing the island area to grow and leading to a smoother coastline. In recent years, in response to the "One Belt And One Road" initiative, Xiamen had more and more frequent exchanges with foreign countries and regions in the fields such as economy and culture. At the same time, it had also increased soaring demands in passenger and freight transport, and actively promoted the construction of ship ports and airports, which also had an important impact on the change of Xiamen's coastline.

\section{Acknowledgments}

This work was financially supported by the Natural Science Foundation of Fujian, China (Grant No. 2019J01769), the Education and Scientific Research Project for Young and Middle-aged Teachers of Fujian Education Department (Grants No. JT180388), and the Science and Technology Pre-Research Project for Introduce Talents of Minjiang University (Grants No. MJY18001).

\section{References}

1. Aedla, R., Dwarakish, G.S., Reddy, D.V. (2015) Automatic shoreline detection and change detection analysis of Netravati-Gurpur River mouth using histogram equalization and adaptive thresholding techniques. Aquat. Procedia, 4: 563 - 570.

2. Moore, L.J. (2000) Shoreline mapping techniques. J. Coast. Res., 16: $111-124$.

3. Lira, C.P., Silva, A.N., Taborda, R., de Andrade, C.F. (2016) Coastline evolution of Portuguese low-lying sandy coast in the last 50 years: An integrated approach. Earth Syst. Sci. Data, 8: 265 - 278.

4. Liu Y.L., Wang X., Ling F., Shuna Xu S., Wang C.C. (2017) Analysis of Coastline Extraction from Landsat-8 OLI Imagery. WATER, 11(9):816-841.

5. Lin T., Li X.H., Zhang G.Q., Zhao Q.J., Cui S.H. (2010). Dynamic analysis of island urban spatial expansion and its determinants: a case study of Xiamen island. Acta Geograhpica Sinica, 65(6): 715-726.

6. Fan X.S., He P., Jia J., Xu Y.Y., Dong J.R. (2017) Ecological carrying capacity evaluation on exploiting coastline for port construction in Xiamen Bay based on habitat protection. Journal of Environmental Engineering Technology, 7(3): 374381.

7. Li J., Bai L.Y., Liu H.M., Liu X.M., Wang Y.Q., Qu R., Nie Y.H. (2016) Impact analysis of port development on regional land use structure based on high resolution remote sensing data. Resources Science, 38(12): 2383-2391.
8. Wang D.H. (2017) Xiamen: integrate into "One Belt And One Road" construction to build an important connectivity hub. http://news.china.com.cn/201709/20/content_41618416.htm.

9. China Ocean Online. (2017) Construction plan for the core area of the 21 st century maritime silk road, Fujian province. http:/www.oceanol.com/zhuanti/201704/12/c63513. html.

10. Gens, R. (2010) Remote sensing of coastlines: Detection, extraction and monitoring. Int. J. Remote Sens., 31: 1819 - 1836.

11. Sánchez-García, E., Pardo-Pascual, J.E., BalaguerBeser, A., Almonacid-Caballer, J. (2015) Analysis of the shoreline Position Extracted from Landsat TM and ETM+ Imagery. In Proceedings of the 36th International Symposium on Remote Sensing of Environmen. Berlin, Germany. pp. 991 - 998.

12. Bruno, M.F., Molfetta, M.G., Mossa, M., Nutricato, R., Morea, A., Chiaradia, M.T. (2016) Coastal observation through Cosmo-SkyMed high-resolution SAR images. J. Coast. Res., 75(sp1), 795-799.

13. Maras, E.E., Caniberk, M., Maras, H.H. (2016) Automatic Coastline Detection Using Image Enhancement and Segmentation Algorithms. Polish Journal of Environmental Studies, 25(6): 2519-2525.

14. Xing K., Zhang B.X., He H.Y. (2017). A Method of Coastline Detection from High-Resolution Remote Sensing Images Based on the Improved Snake Model. In: Urbach H., Zhang G. (eds), 3rd International Symposium of Space Optical Instruments and Applications. Springer, Cham, Switzerland. pp. 419-428.

15. Li, Y., Zhoing, L., Lai, Z., Gan, Z. (2018) Instantaneous coastline extraction from Lidar point cloud and high resolution remote sensing imagery. ISPRS - International Archives of the Photogrammetry, Remote Sensing and Spatial Information Sciences. Beijing, China. pp. 975-979.

16. Lira, C., Taborda, R. (2014) Advances in applied remote sensing to coastal environments using free satellite imagery. In: Finkl, C.W., Makowski, C. (Eds.), Remote Sensing and Modeling. Springer, Cham, Switzerland. pp. 77-102.

17. Pardo-Pascual, J.E., Almonacid-Caballer, J., Ruiz, L.A., Palomar-Vá zquez, J., Rodrigo-Alemany, R. (2014) Evaluation of storm impact on sandy beaches of the Gulf of Valencia using Landsat imagery series. Geomorphology, 214: 388-401.

18. Guo, Q., Pu, R., Zhang, B., Gao, L. (2016) A comparative study of coastline changes at Tampa Bay and Xiangshan Harbor during the last 30 years. 2016 IEEE International Geoscience and Remote Sensing Symposium. Beijing, China. pp. 5185-5188.

19. Wang, X., Liu, Y., Ling, F., Liu, Y., Fang, F. (2017) Spatio-Temporal change detection of Ningbo coastline using Landsat time-series images during 
1976-2015. Isprs International Journal of GeoInformation, 6(3): 68.

20. Wang, X., Liu, Y., Ling, F., Xu, S. (2018) Fine spatial resolution coastline extraction from Landsat8 OLI imagery by integrating downscaling and pansharpening approaches. Remote Sensing Letters, 9(4): 314-323.

21. Zhou C.H., Luo J.C., Yang X.M. (1999) Remote sensing imaging and analysis. Science Press, Beijing. 